\title{
GESTÃO DE RESÍDUOS PÓS-CONSUMO: AVALIAÇÃO DO COMPORTAMENTO DO CONSUMIDOR E DOS CANAIS REVERSOS DO SETOR DE TELEFONIA MÓVEL
}

\author{
Sérgio Luiz do Amaral Moretti \\ Doutor em Ciências Sociais pela Pontifícia Universidade Católica de São Paulo - PUC \\ Professor pelo Programa de Mestrado e Doutorado em Administração - PMDA \\ Universidade Nove de Julho - UNINOVE \\ sergiomoretti@uol.com.br \\ Maria do Carmo Lima \\ Mestre em Administração pelo Programa de Mestrado e Doutorado em Administração - PMDA \\ Universidade Nove de Julho - UNINOVE \\ mcarmo@uninove.br \\ Luciana Helena Crnkovic \\ Doutoranda do Programa de Mestrado e Doutorado em Administração - PMDA \\ Universidade Nove deJulho - UNINOVE \\ crnkovic20@yahoo.com.br
}

\section{RESUMO}

O crescimento do setor de telefonia móvel no Brasil e o descarte inadequado de aparelhos e acessórios de celulares tem provocado um impacto ambiental significativo. O Conselho Nacional do Meio Ambiente Conama publicou em 30 de junho de 1999, a Resolução 257, que visa disciplinar o gerenciamento ambiental adequado de pilhas e baterias usadas por meio da coleta, reutilização, reciclagem, tratamento ou disposição final. O objetivo dessa pesquisa foi verificar os hábitos de descarte dos usuários e como a logística reversa contribui para a gestão de resíduos pós-consumo de equipamentos de telefonia móvel. Essa pesquisa mostrou que, embora a maioria dos fabricantes informe nos seus respectivos sites sobre a forma de descarte das baterias pós-consumo, não é clara a orientação dada ao consumidor sobre o descarte do aparelho celular ou dos acessórios. Em reforço a essa constatação, o survey realizado com usuários universitários de São Paulo revelou que a maioria da amostra desconhece locais apropriados para o descarte e por isso estoca aparelhos e baterias sem uso em casa, muitas vezes dando para crianças brincar, pois recebeu pouca informação sobre $o$ descarte por parte das operadoras e fabricantes. Esses resultados tornaram possível avaliar a importância do impacto ambiental causado pelo descarte inapropriado de aparelhos de telefonia móvel, bem como apontar alternativas para sua redução, como uma comunicação mais eficiente por parte das fabricantes e operadoras, visando a uma maior conscientização do consumidor.

Palavras-chave: Logística Reversa; Gestão de Resíduos: Gestão Ambiental; Impacto Ambiental.

\section{WASTE POST CONSUMPTION MANAGEMENT IN THE MOBILE TELECOM SECTOR: CONTRIBUTIONS OF REVERSE LOGISTICS}

\section{ABSTRACT}

The growth of mobile telephony sector in Brazil has increased the environmental impact of inappropriate disposal of equipment and accessories for mobile phones. The National Environment Council - Conama published on June 30,1999 , Resolution 257 , which aims to control the environmentally sound management of used batteries through the collection, reuse, recycling, treatment or final disposal. The objective of this research was to assess the users' disposal habits and the contribution of reverse logistics of the waste post consumption management in the mobile telephony equipment. The survey showed that while most manufacturers tell in their websites how to dispose of post-consumption batteries, it is not clear consumer advice about the disposal of the cellular phone or accessories. Reinforcing this finding a survey with university students users in São Paulo revealed that the vast majority of the sample unknown suitable sites for disposal, stocks equipment and batteries without using at home, very often giving to kids play, and received little information about the disposal by operators and manufacturers. These results make it possible to evaluate the importance of environmental impact caused by inappropriate waste handling of mobile devices, and to identify alternatives for its reduction as a more efficient communication on the part of manufacturers and operators seeking greater consumer awareness.

Key words: Reverse Logistics; Waste Management; Environmental Management; Environmental Impact.

\footnotetext{
* Apoio recebido do Fundo de Apoio a Pesquisa - FAP/UNINOVE.
} 


\section{INTRODUÇÃO}

Os resíduos, em todas as suas formas e consequiências, têm gerado debates polêmicos e discussões em meios de comunicação de massa, e preocupado ambientalistas, pesquisadores e cidadãos comuns que, com maior ou menor consciência, têm solicitado respostas para esse grande problema (Demajorovic, 2001; Barbieri, 2004; Cajazeira \& Barbieri, 2005).

Segundo o Greenpeace International (2008), são produzidos cerca de 50 milhões de toneladas de resíduos de aparelhos celulares por ano em todo o mundo. Muitos equipamentos contêm substâncias tóxicas, como chumbo, mercúrio e cádmio. O ciclo de obsolescência dos eletrônicos é cada vez mais rápido. No caso dos celulares, novas tecnologias vêm sendo desenvolvidas, atraindo novos usuários e estimulando a troca constante de equipamentos. O setor de telefonia móvel no Brasil cresceu 19,43\%, em 2007, ultrapassando 120 milhões de aparelhos em uso, com mais de $80 \%$ desse total no modo pré-pago, o que indica o crescimento da participação das classes de renda mais baixa (Agencia Nacional de Telecomunicações, 2009).

Esse crescimento leva também ao aumento do consumo de seus periféricos: baterias, acessórios e equipamentos celulares. O descarte inadequado desses equipamentos aumenta os resíduos sólidos, sem contar que o vazamento de materiais químicos das baterias pode poluir os lençóis freáticos, trazendo prejuízos à saúde humana e ao meio ambiente. Com relação às baterias, o Conselho Nacional do Meio Ambiente (Conama) publicou em 30 de junho de 1999, a Resolução 257, que trata do destino final de pilhas e baterias, e visa disciplinar o descarte e o gerenciamento ambientalmente adequado, no que diz respeito à coleta, reutilização, reciclagem, tratamento ou disposição final (Resolução Conama 257, 1999).

Os processos de redução, reaproveitamento e reciclagem tendem a economizar recursos naturais em todo o ciclo de vida do produto, ou seja, desde a extração da matéria-prima até o descarte do produto ou embalagem. Nesse contexto, a gestão de resíduos, por meio da logística reversa, é um importante sistema para a melhoria desses processos, principalmente se usada como uma ferramenta de gestão ambiental preventiva e de longo prazo.

O objetivo dessa pesquisa foi verificar os hábitos de descarte dos usuários e a contribuição da logística reversa na gestão de resíduos pós-consumo de equipamentos de telefonia móvel.

Pretende-se, por meio desse artigo, responder à seguinte questão de pesquisa: Quais os hábitos de descarte dos usuários e como a logística reversa pode contribuir para a gestão de resíduos pós - consumo de telefonia celular na cidade de São Paulo? Para isso adotou-se como referência a Resolução 257 Conama que trata do descarte de pilhas e baterias. Esse trabalho se estrutura da seguinte forma: a revisão da literatura apresenta o perfil da telefonia móvel no Brasil e da Resolução 257/99 Conama, da logística reversa e gestão de resíduos; a seguir apresenta-se a metodologia da pesquisa de campo, os resultados, conclusão e as recomendações para futuras pesquisas.

\section{REVISÃO BIBLIOGRÁFICA}

\subsection{A questão do impacto ambiental de celulares e baterias}

De acordo com a Anatel (2009), na cidade de São Paulo, o mercado de telefonia móvel está concentrado e equilibrado nas mãos de quatro grandes operadoras: Vivo $(29,51 \%)$ Claro $(25,45 \%)$, TIM $(23,73 \%)$ e Oi $(20,94 \%)$. Para atender esse mercado existem sete fabricantes de aparelhos: Gradiente, LG (2008), Motorola (2008), Nokia (2008), Samsung (2008), Siemens (2008) e SonyEricsson (Instituto de Defesa do Consumidor - IDEC, 2008). A oferta de som, imagem, preços acessíveis aos segmentos de menor renda, bem como o acesso a internet têm sido os impulsionadores desse mercado. Em 2009, o Brasil foi considerado o quinto maior mercado do mundo em celulares, com 166 milhões de celulares, atrás apenas da China, Estados Unidos, Rússia e Japão. 
Apesar disso, as evidências empíricas levam a percepção de que milhões de brasileiros desconhecem sobre como fazer o descarte adequado de equipamentos eletroeletrônicos e baterias, $o$ prejuízo ambiental e à saúde que podem causar, quando descartados de forma indevida (Anatel, 2009).

De acordo com Reeberg (2007), considera-se impacto ambiental o efeito provocado por qualquer alteração, benéfica ou adversa, causado pelas atividades humanas ou naturais no meio ambiente. Para o Conama (Resolução Conama 257, 1999) esse impacto ambiental é qualquer alteração nas propriedades físicas, químicas e biológicas do meio ambiente, causada por qualquer forma de matéria ou energia resultante das atividades humanas (MMA, 2008). A NBR ISO $14001 / 2004$ propõe que seja qualquer alteração, benéfica ou adversa, que resulte dos aspectos ambientais de uma organização.

Entre os equipamentos que geram lixo eletrônico, encontra-se o celular. Esses aparelhos são bastante complexos. Em sua composição contêm matérias-primas escassas e valiosas como os metais preciosos, e também componentes de natureza perigosa, como metais pesados das baterias, que, se lançados em locais inadequados, podem vir a contaminar os lençóis freáticos. Um caso emblemático é das baterias de celulares que utilizavam, até algum tempo atrás, o cádmio. Esse metal apresenta grande impacto ambiental, sendo dos constituintes das pilhas aquele que apresenta maior problema para o ambiente, sobretudo em razão de seu elevado tempo de permanência (Gunther \& Reidler, 2002). Uma alternativa ao cádmio, segundo Tenório e Espinosa (2007), é a bateria à base de íons de lítio, que consegue um armazenamento superior de energia, o que aumenta consideravelmente o seu tempo de ação; são também muito leves, pesando cerca de metade de um níquel cádmio equivalente.

As alternativas para reduzir o impacto ambiental das baterias foram impulsionadas pela Resolução 257/99, que obriga os fabricantes a dar um destino final correto às pilhas e baterias no pós-consumo, estabelecendo regras que obrigam aos fabricantes e às empresas que comercializam equipamentos celulares a providenciar o descarte adequado. Pela Resolução 257/99 do Conama, os estabelecimentos que comercializam aparelhos contendo baterias a base de produtos químicos pesados, entre eles o níquel e o cádmio, ficaram obrigados a aceitar dos usuários a devolução das unidades usadas, ou seja, o material deve ser acondicionado adequadamente e armazenado de forma segregada, obedecidas às normas ambientais e de saúde pública pertinentes, bem como as recomendações definidas pelos fabricantes, ou importadores.

Conforme estabelece o Artigo $1^{\circ}$ da Resolução 257/99, as pilhas e baterias, objeto da Resolução, devem ser entregues pelos usuários aos estabelecimentos que comercializam, com vistas à disposição final ambientalmente adequada. Da mesma forma, é importante estimular a coleta e reciclagem de celulares e acessórios, tanto para aproveitar a matéria-prima secundária, quanto para reduzir o impacto desses aparelhos no meio ambiente.

\subsection{Da logística à cadeia da logística reversa}

A logística é o processo de gerenciar estrategicamente a aquisição, movimentação e a armazenagem de materiais, peças e produtos acabados, e o fluxo de informações correlatas, por meio da organização de seus canais de marketing, de modo maximizar a lucratividade, presente e futura, tendo como objetivo o baixo custo (Christopher, 1997). Com a evolução propiciada pela curva de aprendizagem, as empresas passaram a focar esse processo como um todo. O modelo do supply chain management representa o enfoque no gerenciamento da cadeia de suprimentos, no que diz respeito ao gerenciamento do fluxo de materiais, informações e fundos por meio de toda a cadeia de suprimentos, desde os fornecedores dos produtos de componentes, passando pelos montadores finais, distribuidores (atacadistas e varejistas) até chegar ao consumidor final (Rogers \& Tibben-Lembke, 1998; Johnson \& Pyke, 1999).

O gerenciamento da cadeia de suprimentos começa antes da distribuição física, na tentativa de suprir os insumos corretos (matérias-primas, componentes e bens de capital), para, em seguida, 
convertê-los eficientemente em produtos acabados e, finalmente, despachá-los a seus destinos finais. Uma perspectiva ainda mais ampla engloba o estudo de como os próprios fornecedores da empresa obtêm seus insumos, desde as matérias-primas. Infelizmente, a ótica da cadeia de suprimento vê os mercados apenas como pontos de destino.

Nesse contexto, surge a logística reversa, com uma preocupação além dos clientes e fornecedores, apresentando-se como um dos instrumentos de gestão ambiental, por ser uma solução natural para os problemas gerados pelo retorno de vidro, plástico, alumínio, entre outros (Moretti, 2005). A importância da logística reversa se acentuou no início da década de 1980, mas somente na década de 1990 que o seu campo de aplicação foi ampliado, em razão da preocupação crescente com os impactos ambientais.

Existem dois pontos modificadores básicos da logística reversa: o primeiro, de origem ecológica, com manifestações dos mais diversos setores da sociedade (ONGs, associações, cidadãos, consumidores). No outro ponto, fatores como normas, legislação, incentivos fiscais ou outros benefícios impulsionadores da logística reversa. Assim, o segundo tem origem governamental. Enquanto negócio, a logística reversa trata-se do retorno de produtos, da redução de uso de matéria-prima virgem, do uso da reciclagem, da substituição de materiais, do reuso de materiais, da disposição de resíduos, do recondicionamento, do reparo e da remanufatura de produtos (Leite \& Brito, 2000).

A relação entre o fluxo direto e o reverso de produtos descartáveis é mais rápida e fácil do que a dos bens duráveis ou semiduráveis, como é o caso dos equipamentos de telefonia móvel celulares. Por outro lado, a logística reversa de equipamentos, bens duráveis ou semiduráveis, como é o caso dos equipamentos celulares, acessórios e baterias, pode ter o retorno financeiro relacionado à imagem da empresa e não necessariamente com valores monetários perceptíveis nos canais iniciais do processo reverso. Além disso, em relação às baterias, há exigência da Resolução 257/99 do Conama. Dessa forma, o fator ecológico aliado ao fator legal torna-se determinante para a implantação da logística reversa.

As tarefas da logística reversa incluem processar a mercadoria retornada, por razões como dano, sazonalidade, reposição, recall ou excesso de inventário; reciclar materiais de embalagem e reusar containeres; recondicionar, remanufaturar e reformar produtos; dar disposição a equipamentos obsoletos; programar descarte para materiais perigosos; recuperação de ativos. Ainda, segundo Leite (1998) deve-se considerar as variantes, com relação ao tipo de reprocessamento que os materiais podem ter, dependendo das condições como entram no sistema de logística reversa. Os materiais podem retornar ao fornecedor quando houver acordos nesse sentido; serem revendidos se ainda estiverem em condições adequadas para serem comercializados; serem recondicionados, desde que seja justificável economicamente; serem reciclados, se não for possível sua recuperação.

Todas essas alternativas geram materiais reaproveitados, que entram de novo no sistema logístico direto. Finalmente, se não houver outra opção, o destino deve ser o descarte final em locais adequados. A logística reversa pós-consumo operacionaliza o fluxo físico e as informações correspondentes aos bens de consumo descartados pela sociedade, em fim de vida útil ou usados com possibilidade de utilização e resíduos industriais, que retornam ao ciclo de negócios ou ao ciclo produtivo pelos canais de distribuição reversos específicos, ou ciclo reverso tratado a seguir.

O escopo de atuação tradicional de logística reversa, descrito acima, foi ampliado por Barbieri e Dias (2002), para incluir o que eles denominam logística sustentável, que será o conceito adotado nesse trabalho. Seu foco é a recuperação de materiais pós-consumo para ampliar a capacidade de suporte do Planeta, sendo, portanto, um instrumento de gestão ambiental. Segundo os autores, sua implantação necessita o envolvimento de todos os membros da cadeia de suprimentos para sua efetivação. Importante é considerar o nível de relacionamento entre os diversos agentes desse processo: poder público, fabricante, operadora, lojas das operadoras, assistência técnica, recicladora e consumidor. 


\subsubsection{Ciclo reverso}

A vida útil de um bem é entendida como o tempo decorrido desde sua produção original até o momento em que o primeiro possuidor se desembaraça dele (Leite, 2003). Esse desembaraço pode ser dado pela extensão de sua vida útil, por novos possuidores, quando existe o interesse ou a possibilidade de prolongar sua utilização, ou pela sua disponibilização por outras vias, tais como a coleta de lixo urbano, as coletas seletivas e informais, entre outras, passando-o à condição de bem de pós-consumo.

Um centro de distribuição reverso está preparado para o recebimento de mercadorias retornadas por diferentes motivos e de diferentes regiões para que sejam identificadas, selecionadas e destinadas ao canal reverso para dar melhor solução de recaptura de valor. No caso das baterias, algumas fabricantes ou operadoras de telefonia móvel adotaram, como centro de distribuição reverso, as revendedoras de seus produtos. Esses pontos recolhem o material, encaminham a matriz que, por sua vez, encaminha à empresa responsável por sua recuperação. Dessa forma, a grande vantagem desse tipo de centro é consolidar quantidades, permitindo economia de escala em revalorização dos produtos e economizar espaço de estoques nas origens do retorno. Um aumento de quantidade e, certamente, da diversidade de produtos retornados contribui para um maior tempo de reingresso das mercadorias ao ciclo de negócios e um maior risco de perdas de seus valores residuais (Leite, 2003).

Os canais de distribuição reversos podem ser classificados em duas categorias: materiais constituintes e produtos (Leite \& Brito, 2000). No primeiro caso, considera-se que os materiais para reciclagem são extraídos de diferentes produtos pós-consumo e o material resultante pode ser reintegrado ao ciclo produtivo de um produto que será diferente do produto original; esse processo é chamado de ciclo aberto. No segundo, são considerados os materiais extraídos de um determinado produto de pós-consumo e que são reintegrados ao ciclo produto de um produto similar; esse processo recebe o nome de ciclo fechado.

Segundo Leite e Brito (2000), o fator ecológico não é determinante na logística reversa de alguns materiais e isso em razão da baixa quantidade dos materiais recebidos nos canais reversos. Os casos analisados pelos autores tratam de materiais, tais como ferro, alumínio, plásticos, óleo lubrificante, garrafas de PET e latas de alumínio. A análise das influências na decisão da logística reversa desses materiais girou em torno dos seguintes fatores: ambientais, econômicos, sociais e atendimento da legislação vigente, considerando que atende aos padrões de consumo sustentáveis: reduzir, reutilizar, reciclar, incinerar com aproveitamento de energia e dispor os resíduos de forma segura.

A inovação tecnológica tem levado ao crescente descarte de produtos sem que estes tenham, de fato, concluído o tempo de uso, no caso dos aparelhos de telefonia celular, antes do término de sua vida útil. Esse fato reforça a necessidade da utilização de programas de logística reversa pelas empresas, tanto no pós-venda quanto no pós-consumo. A logística reversa pode levar a recuperação de valor do produto ou ao descarte apropriado, sem impacto ao meio ambiente. Quando ocorre a recuperação, o custo da logística reversa é justificado em em razão da nova utilidade que é dada ao produto ou aos resíduos (Demajorovic, 1995; Souza, 2000, Pereira, 2002).

\subsection{Gestão de resíduos sólidos}

Gestão integrada de resíduos sólidos, segundo a Política Nacional de Resíduos Sólidos (PNRS, 2010), é o conjunto de ações voltadas para a busca de soluções para os resíduos sólidos, de forma a considerar as dimensões política, econômica, ambiental, cultural e social, com controle social e sob a premissa do desenvolvimento sustentável.

No dia-a-dia é possível adotar pequenas ações que levem em conta os impactos da compra, uso ou descarte de produtos ou serviços, considerando os recursos naturais como a água, a escolha das empresas que adotem responsabilidade ambiental. Nesse sentido, Souza (2000) considera que se 
não sendo possível evitar o consumo, deve-se buscar a reutilização por meio da reciclagem. A reciclagem é um processo industrial que converte o resíduo pós-consumo em matéria-prima secundária. A reciclagem, além de economizar energia, poupa recursos naturais e traz de volta ao ciclo produtivo o que poderia estar no lixo.

Os aterros são locais para disposição ou aterramento do lixo sobre o solo e deve ser diferenciado, tecnicamente, em aterro sanitário, aterro controlado e aterro comum ou vazadouro, mais conhecido como lixão (Mazzer \& Cavalcanti, 2004). O aterro sanitário trata-se de um processo utilizado para a disposição de resíduos sólidos no solo, particularmente, lixo domiciliar, que fundamentado em critérios de engenharia e normas operacionais específicas, permite a confinação segura em termos de controle de poluição ambiental, proteção à saúde pública. Os gases liberados durante a decomposição são captados e podem ser queimados por meio do sistema de purificação de ar ou ainda podem ser utilizados como fonte de energia (aterros energéticos). Segundo a Associação Brasileira de Normas Técnicas (ABNT, 1996), o aterro sanitário não deve ser construído em áreas sujeitas à inundação. Entre a superfície inferior do aterro e o mais alto nível do lençol freático deve haver uma camada de espessura mínima de $1,5 \mathrm{~m}$ de solo insaturado. O nível do solo deve ser medido durante a época de maior precipitação pluviométrica da região. $\mathrm{O}$ solo deve ser argiloso. $\mathrm{O}$ aterro deve ser localizado a uma distância mínima de 200 metros de qualquer curso d'água. A arborização deve ser adequada nas redondezas para evitar erosões, espalhamento da poeira e retenção dos odores.

O lixão é um local onde há uma inadequada disposição final de resíduos sólidos, que se caracteriza pela simples descarga sobre o solo, sem medidas de proteção ao meio ambiente ou à saúde pública. Os resíduos lançados em lixões, em razão da proliferação de moscas, mosquitos, baratas, ratos, todos vetores de doenças, geração de maus odores, acarretam sérios problemas à saúde pública, além de poluir o solo e as águas superficiais e subterrâneas por meio do chorume, produzido pela decomposição da matéria orgânica contida no lixo.

$\mathrm{O}$ aterro controlado funciona como intermediário entre o aterro sanitário e o comum. A diferença que há em relação ao aterro comum é que o controlado recebe uma cobertura de material inerte, areia ou terra, após a disposição do lixo.

A recuperação e o tratamento de áreas degradadas onde funcionavam aterros controlados e lixões, é dispendiosa e quanto mais contaminada e maior for a área a ser recuperada, mais recursos serão necessários, prejudicando a sustentabilidade ambiental (Souza, 2000).

De acordo com a Associação Brasileira de Empresas de Tratamento de Resíduos Especiais (Abetre, 2008), a incineração é um processo de decomposição térmica, que reduz peso, volume e periculosidade dos resíduos, com a consequente eliminação da matéria orgânica e das características de patogenicidade (capacidade de transmissão de doenças) por meio da combustão controlada. A redução de volume é geralmente superior a 90\% e em peso, superior a 75\% (Abetre, 2008).

Para a garantia do meio ambiente, a combustão tem que ser continuamente controlada. Com o volume atual dos resíduos industriais perigosos e o efeito nefasto quanto à sua disposição incorreta, com resultados danosos tanto à saúde humana quanto ao meio ambiente, é necessário todo cuidado no acondicionamento, na coleta, no transporte, no armazenamento, tratamento e disposição desses materiais. No Brasil, são 2,9 milhões de toneladas de resíduos industriais perigosos produzidos a cada 12 meses e apenas 600 mil são dispostos de modo apropriado. Do resíduo industrial tratado, $16 \%$ vão para aterros, $1 \%$ é incinerado e os $5 \%$ restantes são coprocessados, ou seja, transformam-se, por meio de queima, em parte da matéria-prima utilizada na fabricação de cimento (Abetre, 2008).

Percebe-se que existem vários destinos que podem ser dados para os aparelhos celulares e periféricos pós-consumo, tudo dependerá da política municipal a se adotada para o tratamento dos resíduos sólidos urbanos. Nesse contexto, de um lado, operadoras, fabricantes, lojas e governo deveriam assumir responsabilidades legais e, por seu poder de agência, deveriam mobilizar e intervir decididamente no sistema. Por outro, o consumidor, que é o que utiliza o aparelho, deve 
ficar, em última instância, responsável pelo descarte. A investigação empírica a seguir procura desvendar essa questão.

\section{MÉTODO DE PESQUISA}

Com o objetivo de analisar a contribuição da logística reversa no gerenciamento de resíduos gerados por aparelhos de telefones celulares e baterias, foi realizada uma pesquisa em duas etapas, envolvendo os principais atores que formam a cadeia de logística reversa do setor de telefonia móvel no Brasil. Na primeira fase, desenvolveu-se uma pesquisa exploratória em fontes secundárias de dados externos, que permitiu conhecer melhor o tema (Malhotra, 2001). O objetivo desse levantamento foi verificar como as operadoras e fabricantes orientam os consumidores sobre o descarte correto de aparelhos, acessórios e baterias. Utilizou-se, como instrumento de coleta de dados, um roteiro cobrindo os seguintes pontos: postura da gestão ambiental da empresa e se ela indica a forma de descarte de baterias e acessórios.

$\mathrm{Na}$ segunda fase, desenvolveu-se uma investigação quantitativa descritiva por meio de um survey para compreender, principalmente, o comportamento dos usuários em relação aos hábitos de descarte de baterias e aparelhos celulares, procurando descrevê-los, classificá-los e interpretá-los (Freitas, Oliveira, Saccol \& Moscarola, 2000). A amostra foi de conveniência sendo os participantes usuários de telefonia móvel da cidade de São Paulo. Os questionários foram aplicados aos usuários que já tiveram dois ou mais aparelhos celulares, procurando levantar como o descarte do equipamento, dos acessórios e da bateria foi realizado.

A primeira parte do questionário procurou caracterizar o respondente, para isso foram utilizadas questões fechadas sobre: sexo, idade, renda, número de troca de aparelhos celulares (contando com o atual), entre outros itens. Na segunda parte, as questões tinham como objetivo obter informações a respeito do conhecimento do usuário sobre a legislação Conama 257/99 e os locais de descarte, além de obter informações sobre marca do aparelho e da operadora, se conhecem informações do fabricante ou da operadora sobre a forma de descarte e se descarta da forma indicada na resolução ou pelas empresas.

\section{ANÁLISE E DISCUSSÃO DOS RESULTADOS}

Essa seção tem como objetivo expor os principais resultados obtidos nas pesquisas, tanto as realizadas nos sites das empresas fabricantes e operadoras, quanto nas obtidas por meio dos questionários aplicados junto à amostra. O eixo orientador desses resultados é como já mencionado, a Resolução Conama 257/99, que regulamenta a destinação final das pilhas e baterias.

\subsection{Operadoras e fabricantes}

As três operadoras têm conhecimento da exigência legal sobre o descarte das baterias, todas têm programas de logística reversa, tanto das baterias quanto de equipamentos celulares e acessórios e fornecem informações no site sobre o descarte tanto das baterias quanto dos aparelhos, carregadores e acessórios pós-consumo de telefonia móvel. O Quadro 1 apresenta a síntese das informações das operadoras nos seus respectivos sites.

\begin{tabular}{|c|l|l|}
\hline Empresa & $\begin{array}{c}\text { Tem informações no site sobre o } \\
\text { descarte de baterias: }\end{array}$ & \multicolumn{1}{c|}{$\begin{array}{c}\text { Tem informações no site sobre o descarte dos aparelhos, } \\
\text { carregadores e acessórios. }\end{array}$} \\
\hline Claro & $\begin{array}{l}\text { Tem instruções sobre descarte de de } \\
\text { bateria }\end{array}$ & $\begin{array}{l}\text { Há informações sobre o descarte de aparelhos de telefonia celular e } \\
\text { acessórios, mas requer uma busca mais detalhada. }\end{array}$ \\
\hline TIM & $\begin{array}{l}\text { Tem instruções sobre descarte de } \\
\text { baterias. }\end{array}$ & $\begin{array}{l}\text { Há informações sobre o descarte de aparelhos de telefonia celular e } \\
\text { acessórios, mas requer uma busca mais detalhada. }\end{array}$ \\
\hline Vivo & $\begin{array}{l}\text { Tem instruções sobre descarte de } \\
\text { bateria. }\end{array}$ & $\begin{array}{l}\text { Há informações sobre o descarte de aparelhos de telefonia celular e } \\
\text { acessórios em local de fácil visualização. }\end{array}$ \\
\hline \multicolumn{3}{|c}{ Quadro 1: Síntese das informações das operadoras } \\
Fonte: Elaborado pelos autores.
\end{tabular}

Revista de Gestão Social e Ambiental - RGSA, São Paulo, v. 5, n. 1, p. 03-14, jan./abr., 2011. 
As informações obtidas dos sites das fabricantes mostram que algumas adotam ações tanto de descarte da bateria quanto de equipamento. Com relação ao descarte das baterias, das sete empresas pesquisadas, apenas a Gradiente (2007) não tem instruções sobre seu descarte. Com relação ao descarte do equipamento, a Gradiente, a LG, a Samsung, a Siemens e a Sony (2008) não fornecem instruções sobre descarte de aparelhos de telefonia celular, apenas a Motorola e a Nokia fornecem tais informações. O Quadro 2 apresenta um panorama das empresas no que diz respeito à logística reversa das baterias, equipamentos, acessórios de telefonia móvel.

\begin{tabular}{|c|l|l|}
\hline Empresa & \multicolumn{1}{|c|}{ O que diz sobre descarte de bateria } & \multicolumn{1}{c|}{ O que diz sobre descarte do produto } \\
\hline Gradiente & Não tem instruções sobre descarte de bateria. & $\begin{array}{l}\text { Não há instruções sobre descarte de aparelhos de } \\
\text { telefonia celular e acessórios. }\end{array}$ \\
\hline LG & $\begin{array}{l}\text { Tem instruções sobre descarte de bateria, mas de } \\
\text { difícil localização no site para usuário. }\end{array}$ & $\begin{array}{l}\text { Não há instruções sobre descarte de aparelhos de } \\
\text { telefonia celular. }\end{array}$ \\
\hline Motorola & $\begin{array}{l}\text { Tem instruçóes claras sobre descarte de bateria } \\
\text { no portal de celulares. }\end{array}$ & $\begin{array}{l}\text { Há informações sobre o descarte de aparelhos de } \\
\text { telefonia celular e acessórios }\end{array}$ \\
\hline Nokia & $\begin{array}{l}\text { Tem instruções claras sobre descarte de bateria } \\
\text { no portal de celulares. }\end{array}$ & $\begin{array}{l}\text { Há informações sobre o descarte de aparelhos de } \\
\text { telefonia celular e acessórios }\end{array}$ \\
\hline Samsung & $\begin{array}{l}\text { Tem instruções sobre descarte de bateria, mas de } \\
\text { difícil localização no site para o usuário. }\end{array}$ & $\begin{array}{l}\text { Não há instruções sobre descarte de aparelhos de } \\
\text { telefonia celular e acessórios }\end{array}$ \\
\hline Siemens & $\begin{array}{l}\text { Tem instruções claras sobre descarte de bateria } \\
\text { na página de celulares. }\end{array}$ & $\begin{array}{l}\text { Não há instruções sobre descarte de aparelhos de } \\
\text { telefonia celular. }\end{array}$ \\
\hline $\begin{array}{c}\text { Sony- } \\
\text { Ericsson }\end{array}$ & $\begin{array}{l}\text { Tem instruções claras sobre descarte de bateria } \\
\text { no portal de celulares. }\end{array}$ & $\begin{array}{l}\text { Não há instruções sobre descarte de aparelhos de } \\
\text { telefonia celular e acessórios }\end{array}$ \\
\hline
\end{tabular}

Quadro 2: Síntese das informações dos fabricantes na internet

Fonte: Adaptado de IDEC (2008).

Dentro da cadeia logística da reciclagem, empresas como a Recellular e Suzaquim têm desempenhado um papel importante. A empresa americana Recellular e a Vivo (2008) no Brasil fecharam uma parceria em que os clientes podem entregar, nas próprias lojas das operadoras, as baterias, os equipamentos, os carregadores e os acessórios. No Brasil, a Vivo (2008) foi à primeira operadora a implantar uma ampla ação de logística reversa de celulares, comunicando aos seus clientes por meio de torpedos enviados aos seus celulares, bem como por meio de informações disponibilizadas no portal e nas lojas da empresa.

Com relação à reforma e reciclagem, a pesquisa levantou que a Suzaquim recebe materiais provenientes dos celulares da empresa GM\&C que tritura o equipamento (exceto a bateria) antes de enviar à Suzaquim que, por sua vez, transformará os resíduos em matéria-prima para corantes de pisos cerâmicos, vidros e refratários. A empresa tem capacidade para recolher 250 toneladas, mas consegue captar apenas 30 toneladas mensalmente. A pesquisa com o usuário mostrou que o volume de recolhimento desses equipamentos é baixo, haja vista que apenas cerca de $10 \%$ dos usuários responderam que entregaram a bateria ou o celular na operadora, fabricante ou assistência técnica.

\subsection{Usuários de telefonia móvel}

Os resultados demográficos do survey entre os estudantes de graduação mostraram um total de 376 respondentes, sendo $38 \%$ do sexo masculino e $62 \%$ do sexo feminino, distribuídos em $12,2 \%$ menores do que 20 anos de idade; $42,5 \%$ entre 21 e 25 anos e 25,3\% entre 26-30 anos e os demais $20 \%$ da amostra com idade superior a 31 anos. No que concerne à renda familiar, constatouse que $22,1 \%$ tinham menos que três salários mínimos; $41,3 \%$ entre três e cinco salários mínimos e $18,1 \%$ entre seis e dez salários mínimos, os demais $18,5 \%$ se situaram na faixa superior a 11 salários mínimos. Esses resultados iniciais refletem bem a amostra de universitários da Instituição de Ensino Superior - IES escolhida, notoriamente de Classe C. Quanto às operadoras utilizadas, a Tabela 1 resume a preferência dos respondentes. 
Tabela 1: Qual a operadora de telefonia móvel que você utiliza (RM)?

\begin{tabular}{c|c|c}
\hline Claro & 127 & $33,8 \%$ \\
\hline Tim & 127 & $33,8 \%$ \\
\hline Vivo & 97 & $25,8 \%$ \\
\hline Oi & 88 & $23,4 \%$ \\
\hline Outras & 6 & $1,6 \%$ \\
\hline Total & 376 & \\
\hline
\end{tabular}

Fonte: Dados da pesquisa.

Em relação à posse de celulares, a Tabela 2 indica que grande parte desses universitários, mesmo pertencendo à classe $\mathrm{C}$, já havia adquirido mais do que um aparelho, sendo notável que $26,1 \%$ tenham adquirido três aparelhos e que $25 \%$ dos respondentes mais do que quatro. Esse resultado parece indicar, como observado na revisão da literatura (Leite \& Brito, 2000, Souza, 2000, Gunther \& Reidler, 2002), que o estoque de resíduos tanto de aparelhos quanto de seus complementos pode se tornar um grande desafio ambiental, caso não seja equacionado um procedimento adequado de seu descarte. Esses resultados são agravados pelo fato de que o tempo médio para efetuar a troca de aparelhos chega a $25,6 \%$ para o prazo de um ano e $39,4 \%$ para o prazo de dois anos. Assim, 65\% dos respondentes trocam de celulares em um prazo de dois anos, situação que deve se agravar à medida que mais usuários entram no mercado, motivados pela redução de preços dos aparelhos.

Tabela 2: Até o momento, quantos aparelhos celulares você teve?

\begin{tabular}{c|c|c}
\hline 0 & 1 & $0,2 \%$ \\
\hline Um & 94 & $25,0 \%$ \\
\hline Dois & 89 & $23,7 \%$ \\
\hline Três & 98 & $26,1 \%$ \\
\hline Quatro & 47 & $12,5 \%$ \\
\hline Cinco ou mais & 47 & $12,5 \%$ \\
\hline Total & 376 & \\
\hline \multicolumn{2}{r}{} \\
\hline
\end{tabular}

A Tabela 3 aponta para um quase empate entre os 37,5\% que mencionaram o motivo que o anterior apresentou defeito e, os 34,8\% que alegaram ter interesse em nova tecnologia. Se somarmos também os $19,7 \%$ que apontaram interesse em novo design e os 1,1\% de apelo da mídia e os 7,8\% de oferta da operadora, chegamos a um total de $62,3 \%$ para os quesitos relacionados com o incentivo ao consumo. No atual cenário, portanto é importante aceitar que o movimento de mercado ocorre em direção ao aumento da oferta e que o desejo dos consumidores é obter um novo aparelho celular pela simples razão de que se tornou uma ferramenta da vida moderna e dos processos de integração social, principalmente dos jovens. Vale destacar que $54,7 \%$ dos respondentes têm até 25 anos de idade. A Tabela 3 mostra os resultados.

Tabela 3 - Porque você trocou de aparelho celular (RM)?

\begin{tabular}{c|c|c}
\hline O anterior apresentou defeito & 139 & $37,5 \%$ \\
\hline Trocou de operadora & 52 & $14,0 \%$ \\
\hline Trocou de pré-pago para pós pago & 21 & $5,7 \%$ \\
\hline Trocou de pós-pago para pré-pago & 6 & $1,6 \%$ \\
\hline Interesse em nova tecnologia & 129 & $34,8 \%$ \\
\hline Interesse em novo design & 73 & $19,7 \%$ \\
\hline Apelo da mídia & 4 & $1,1 \%$ \\
\hline
\end{tabular}




\begin{tabular}{c|c|c}
\hline Oferta da operadora & 29 & $7,8 \%$ \\
\hline Ganhou de presente & 55 & $14,8 \%$ \\
\hline Outro motivo & 65 & $17,5 \%$ \\
\hline Total & 371 & \\
\hline
\end{tabular}

Fonte: Dados da pesquisa.

Tal descoberta está totalmente alinhada com os $65 \%$ que trocaram de aparelho nos últimos dois anos, como já tinha sido mencionado anteriormente, parecendo indicar que o grande desafio aponta para uma maior conscientização dos consumidores sobre os cuidados com o descarte. Contudo os resultados mostram um desacerto nesse quesito, já que 86,4\% declararam não terem sido alertados sobre procedimentos de descarte quando compraram o aparelho. Tal número parece indicar a necessidade de se reforçar a vigilância sobre a responsabilidade dos vendedores (operadoras e lojas, por exemplo) quanto às necessidades de iniciar o processo de conscientização, no momento da compra. Em relação aos poucos 13,6\% que declararam terem sido alertados; 48,9\% o foram na loja e $31,1 \%$, pelo manual do fabricante. O destaque entre as fabricantes foi a Motorola com $21,7 \%$ e a LG com $13,0 \%$ e a Vivo com $13,0 \%$ entre as operadoras.

Interessante notar que as empresas de reciclagem foram responsáveis por $11,1 \%$ das lembranças parecendo indicar que um esforço sinérgico em toda a cadeia logística do descarte deve ser considerado (Demajorovic, 1995, Souza, 2000, Pereira, 2002).

Uma das questões mais importantes propostas pelo estudo foi a identificação dos hábitos de descarte dos consumidores. Os resultados parecem indicar que ainda há um grande caminho a percorrer para se atingir níveis mais seguros de descarte de materiais prejudiciais à saúde e de manipulação pela maioria da população. A Tabela 4 mostra que 76,2\% ainda guardam os aparelhos em casa expondo a família ao possível contato com materiais tóxicos, o que é agravado para o fato de que $10,3 \%$ deram para crianças brincar. Vale destacar que $19,6 \%$, que procederam o descarte da forma correta constituem uma minoria alarmante para os padrões de consumo que se estabeleceram nos últimos anos, o que demonstra a assimetria entre o esforço para o consumo e o pouco esforço para preservação de um ambiente.

Tabela 4: Como você descartou os equipamentos anteriores?

\begin{tabular}{|c|c|c|}
\hline No lixo de casa & 52 & $15,3 \%$ \\
\hline Guardou em casa & 172 & $50,6 \%$ \\
\hline Deu para criança & 35 & $10,3 \%$ \\
\hline Deu para conhecido & 93 & $27,4 \%$ \\
\hline Vendeu & 72 & $21,2 \%$ \\
\hline Entregou na operadora & 14 & $4,1 \%$ \\
\hline Entregou na fábrica & 0 &, $0 \%$ \\
\hline Entregou na assistência técnica & 3 & $9 \%$ \\
\hline Entregou no papa-pilha de banco ou shopping & 22 & $6,5 \%$ \\
\hline Total & 340 & \\
\hline
\end{tabular}

Fonte: Dados da pesquisa.

Pode-se reforçar o argumento acima, tendo como base o resultado de que $76,6 \%$ dos respondentes não conheciam nenhum posto de coleta de baterias pós-uso e que $87,2 \%$ não conheciam postos de coleta para os aparelhos pós-uso. Outro elo da cadeia logística mostra falha, alinhando-se a falta de procedimentos adequados no momento da compra. Por outro lado, o melhor desempenho das baterias mostra a vantagem de um trabalho que já dura um tempo maior do que os aparelhos e também de iniciativas como papa-pilha. A tabela 5 mostra alguns dos destaques das respostas coletadas. 
Tabela 5: Você conhece algum posto de coleta pós-uso? Qual?

\begin{tabular}{l|c|c}
\hline Bco. Real & 7 & $8,9 \%$ \\
\hline Drogaria São Paulo & 3 & $3,8 \%$ \\
\hline Lojas de vendas de celulares & 9 & $11,4 \%$ \\
\hline Lojas Motorola & 2 & $2,5 \%$ \\
\hline Lojas Vivo & 4 & $5,1 \%$ \\
\hline Na empresa que trabalha & 8 & $10,1 \%$ \\
\hline Nos Shoppings & 3 & $3,8 \%$ \\
\hline Total & 79 & \\
\hline
\end{tabular}

Fonte: Dados da pesquisa.

Como pode ser observado, as respostas se resumem a 79 dos respondentes $(21,0 \%)$. As demais respostas, dos restantes 297 respondentes, ficaram limitadas a 1,3\% cada uma indicando a pulverização das alternativas, inclusive relativa a empresas, escolas, shoppings e lojas de operadoras e fabricantes.

Em relação à responsabilidade de cada um pelo descarte adequado, a Tabela 6 mostra uma dispersão de alternativas, resultante da aparente falta de informação que favorece a desinformação do consumidor.

Tabela 6 - Em sua opinião de quem é a responsabilidade pelo descarte adequado?

\begin{tabular}{l|c|c|c|c}
\hline & \multicolumn{2}{|c|}{ Aparelhos } & \multicolumn{2}{c}{ Baterias } \\
\hline Dos usuários (consumidor/ cliente) & 217 & $57,9 \%$ & 194 & $51,9 \%$ \\
\hline Da operadora & 55 & $14,7 \%$ & 59 & $15,8 \%$ \\
\hline Da empresa Reciclagem & 37 & $9,9 \%$ & 51 & $13,6 \%$ \\
\hline Da Anatel & 11 & $2,9 \%$ & 11 & $2,9 \%$ \\
\hline Dos fabricantes & 136 & $36,3 \%$ & 136 & $36,4 \%$ \\
\hline Da Assistência Técnica & 6 & $1,6 \%$ & 10 & $2,7 \%$ \\
\hline Do Ibama & 4 & $1,1 \%$ & 4 & $1,1 \%$ \\
\hline Outros? & 9 & $2,4 \%$ & & 5 \\
\hline Total & 375 & $100,0 \%$ & 374 & $1,3 \%$ \\
\hline
\end{tabular}

Fonte: Dados da pesquisa.

Desse modo, a assimetria da responsabilidade se revela. O consumidor assume a maior parte dela, em ambos os casos, entretanto os fabricantes, operadoras, lojas e governo omitem sua parte na questão, pelos baixos índices de respostas em suas opções. Esse fato revela a omissão do processo de elos importantes da cadeia responsáveis pela logística de descarte e um consumidor que já tem consciência de sua responsabilidade nesse processo (Rogers \& Tibben-Lembke, 1998).

\section{CONSIDERAÇÕES FINAIS}

O objetivo geral dessa pesquisa foi verificar a contribuição da logística reversa na gestão de resíduos pós-consumo dos equipamentos de telefonia móvel. Concluiu-se que as empresas, operadoras e fabricantes, atendem a Resolução 257/99, mas esse procedimento não é suficiente para resolver o problema, pois o volume de descarte inadequado supera, em muitas vezes, o do descarte adequado. Foi possível verificar também que as três operadoras pesquisadas, Claro, Tim (2008), Vivo, têm informações nos portais na internet sobre o descarte adequado dos celulares, tanto das baterias quanto dos equipamentos e que, quase $100 \%$ das fabricantes fazem o mesmo, com exceção da Gradiente, em relação às baterias. E duas delas, Motorola e Nokia, informam também sobre o descarte dos equipamentos e acessórios.

As iniciativas da Vivo e da Recellular revelam a existência de tecnologia e conhecimento para reformar os equipamentos celulares pós-uso. Além disso, verificou-se que a empresa Suzaquim 
recebe materiais provenientes dos celulares de outras empresas que trituram o equipamento (exceto a bateria) para a transformação dos resíduos em matéria-prima secundária.

Apesar de a incineração ser um destino final, quando feita da forma adequada, com fornos equipados de forma a minimizar os lançamentos dos resíduos poluentes na atmosfera, para muitos produtos pós-consumo, no caso dos celulares, não é adequada. Esses aparelhos não deveriam ser incinerados, pois tanto o reuso quanto a reciclagem podem ser incentivados. As baterias correm o risco de explodir e por isso não podem ser incineradas. Quando inservíveis, os celulares podem ser triturados, como é feito pela Suzaquim, e transformados em matéria-prima para outros produtos.

Já com relação à bateria, o problema é a poluição química que pode contaminar os lençóis freáticos e acarretar sérios riscos à saúde humana. Além disso, a lei 257/99 determina, por um lado, o descarte e a adequação final das baterias, justamente por causa de suas especificidades, ou seja, por conter componentes químicos. Por outro, quando da constituição da Lei 257/99, o maior volume de baterias era à base de níquel e cádmio. E, como visto anteriormente elas já começaram a ser fabricadas à base de íons de lítio, que representam menor risco à saúde humana e ao meio ambiente.

Com esse trabalho foi possível discutir o impacto ambiental do descarte de aparelhos de telefonia móvel, bem como as alternativas para a redução desse impacto; e verificar por meio de informações nos portais das empresas fabricantes de aparelhos celulares e das operadoras que não oferecem informações suficientes sobre as ações de pós-consumo dos equipamentos, acessórios e baterias, em relação às exigências da Resolução Conama 257/99.

Algumas próximas pesquisas podem ser sugeridas, como: estender a investigação para os representantes das fabricantes, das operadoras, do Ibama, e das empresas de reciclagem para criar alternativa de cruzar os resultados da análise da cadeia logística reversa de equipamentos celulares com os hábitos dos usuários. Esse estudo, também, abre oportunidades para o campo do comportamento do consumidor, no sentido de aprofundar a compreensão da relação que o usuário estabelece com aparelhos celulares e baterias e, principalmente sua atitude quanto ao descarte.

A contribuição gerencial desse estudo foi mostrar as oportunidades que se apresentam, tanto para fabricantes quanto para operadoras, de aproximação com seus consumidores, por meio de uma relação positiva com base na comunicação da preservação do ambiente. Para isso, basta empenho para começar a disponibilizar informações eficientes em seus sites e manuais.

\section{REFERÊNCIAS}

Abetre. Associação Brasileira de Empresas de Tratamento de Resíduos. (2008). Pesquisa geral no site. Recuperado em 25 de janeiro, 2008, de http://www.abetre.org.br/quem.asp

Agencia Nacional de Telecomunicações. (2009). Brasil tem 7,16 milhões de domicílios com TV por assinatura. Recuperado em 2 de dezembro, 2009, de http://www.anatel.gov.br/Portal/exibirPortalInternet.do

Associação Brasileira de Normas Técnicas. (1996). NBR 8419: apresentação de projetos de aterros sanitários de resíduos sólidos urbanos. Rio de Janeiro: Autor.

Barbieri, J. C. (2004). Gestão ambiental empresarial: conceitos, modelos e instrumentos. São Paulo: Saraiva.

Barbieri, J. C., \& Dias, M. (2002). Logística reversa como instrumento de programas de produção e consumo sustentáveis. Revista Tecnologística, 6 (77), 58-69.

Cajazeira, J. E. R., \& Barbieri, J. C. (2005). A futura norma ISO 26000 sobre responsabilidade 
social: barreira não tarifária ou comércio justo? [CD-ROM]. In Anais do Encontro Nacional sobre Gestão Empresarial e Meio Ambiente, 8. Rio de Janeiro, BR.

Christopher, M. (1997). Logística e gerenciamento da cadeia de suprimentos: estratégias para a redução de custos e melhoria dos serviços. São Paulo: Pioneira.

Claro. (2007). Recicle celulares e baterias. Recuperado em 20 de dezembro, 2007, de http://www.claro.com.br/portal/artigo.do?method=showArtigo\&channelId=6b89603541203110 VgnVCM1000000a08150aRCRD\&origem $=$ Conhe\%E7a\%20a\%20Claro\&item=Responsabilida de\%20Social

Demajorovic, J. (1995). Da política tradicional de tratamento de lixo à política de gestão de resíduos sólidos: as novas prioridades. Revista de Administração de Empresas, 35(3), 88-93.

Demajorovic, J. (2001). Sociedade de risco e responsabilidade socioambiental. São Paulo: Senac.

Freitas, H., Oliveira, M., Saccol, A. Z., \& Moscarola, J. (2000). O método de pesquisa survey. Revista de Administração, 35(3), 105-112.

Gradiente. (2007). Linha do tempo. Recuperado em 20 de maio, 2007, de http://www.gradiente.com/site/empresa/pt/linhadotempo.asp

Greenpeace International. (2008). Pesquisa geral no site. Recuperado em 13 de agosto, 2008, de http://www.greenpeace.org

Gunther, W. M. R., \& Reidler, N. (2002). Impactos sanitários e ambientais devido aos resíduos gerados por pilhas e baterias usadas. Recuperado em 20 de julho, 2008, de http://www.cepis.ops-oms.org/bvsaidis/mexico26/iv-068.pdf

Instituto de Defesa do Consumidor. (2008). Pesquisa geral no site. Recuperado em 20 de maio, 2008, de http://www.idec.org.br/arquivos/quatros_sites_celulares.doc

Johnson, M. E., \& Pyke, D. F. (1999). Supply chain management. Hanover: Darmouth College.

Leite, P. R. (1998). Canais de distribuição reversos: conceitos. Revista Tecnologística, 28, 22-27.

Leite, P. R. (2003). Logística reversa: meio ambiente e competitividade. São Paulo: Prentice Hall.

Leite, P. R., \& Brito, E. P. Z. (2000). Fatores que influenciam a reciclagem de materiais em canais de distribuição reversos [CD-ROM]. In Encontro da Associação Nacional de Pós-Graduação e Pesquisa em Administração, 24. Florianópolis, BR.

LG Sistemas. (2008). Pesquisa geral no site. Recuperado em 26 de novembro, 2008, de http://www.lg.com.br

Malhotra, N. K. (2001). Pesquisa de marketing: uma orientação aplicada. Porto Alegre: Bookman.

Mazzer, C., \& Cavalcanti, O. A. (2004). Introdução à gestão ambiental de resíduo. Infarma, 16(1112), 67-77.

Moretti, S. L. A. (2005). A trama e a urdidura: responsabilidade social das empresas. Tese de 
Doutorado, Programa de Pós Graduação em Ciências Sociais, Pontifícia Universidade Católica de São Paulo, São Paulo.

Motorola. (2008). Sobre a Motorola. Recuperado em 26 de novembro, 2008, de http://www.motorola.com/content.jsp?globalObjectId=486-913

Nokia. (2008). Pesquisa geral no site. Recuperado em 18 de janeiro, 2008, de http://www.nokia.com.br

Pereira, R. S. (2002). Desenvolvimento sustentável como responsabilidade social das empresas: um enfoque ambiental. São Paulo: Lorosal.

Reeberg, J. H. (2007). Metodologia Sebrae 5 menos que são mais - redução de desperdício [CDROM]. In Encontro Nacional sobre Gestão Empresarial e Meio Ambiente, 11. Curitiba, BR.

Resolução Conama (1999) no 257, de 30 de junho de 1999. Diário Oficial da União - 22/07/1999. Recuperado em 12 de setembro, 2008 de www.siam.mg.gov.br/sla/download.pdf?idNorma=48

Rogers, D. S., \& Tibben-Lembke, R. S. (1998). Going backwards: reverse logistics trends and practices. Recuperado em 20 de agosto, 2007, de http://www.rlec.org/reverse.pdf

Samsung. (2008). Pesquisa geral no site. Recuperado em 15 de outubro, 2008, de http://www.samsung.com.br

Siemens. (2008). Procedimento de coleta de baterias e pilhas recarregáveis. Recuperado em 20 de maio, 2008, de http://gigaset.siemens.com/shc/0,1935,br_pt_0_47104_rarnrnrnrn,00.html

Sony Ericsson. (2008). Controle de substâncias. Recuperado em 10 de abril, 2008 de, $\mathrm{http} / / / \mathrm{www}$. sonyericsson.com/cws/companyandpress/sustainability/consciousdesign? $\mathrm{lc}=\mathrm{pt} \& \mathrm{cc}=$ br

Souza, M. T. S. (2000). Organização sustentável: indicadores setoriais dominantes para a avaliação da sustentabilidade - análise de um segmento do setor de alimentação. Tese de Doutorado, Escola de Administração de Empresas, Fundação Getúlio Vargas, São Paulo.

Tenório, J. A. S., \& Espinosa, D. C. R. (2007). Reciclagem de pilhas e baterias. Recuperado em 20 de julho, 2007, de http://www.cepis.ops-oms.org/bvsare/e/proypilas/pilas.pdf

Tim. (2008). Pesquisa geral no site. Recuperado em 18 de janeiro, 2008, de http://www.tim.com.br/portal/site/PortalWeb

Vivo. (2008). Pesquisa geral no site. Recuperado em 18 de janeiro, 2008, de http://www.vivo.com.br/portal/institucional_vivo_avivo.php

Data do recebimento do artigo: 16/12/2009

Data do aceite de publicação: 20/03/2011

Revista de Gestão Social e Ambiental - RGSA, São Paulo, v. 5, n. 1, p. 03-14, jan./abr., 2011. 